\title{
Dynamic Corrosion-induced Cracking Process of RC Considering Effect of Initial Defects
}

\author{
Xiao-Gang Zhang*1, Yan-Gang Zhao ${ }^{2}$ and Zhao-Hui Lu ${ }^{3}$ \\ ${ }^{1}$ Associate Professor, College of Civil Engineering, Shenzhen University, \\ Shenzhen Municipal Key Laboratory for Durability of Civil Engineering Structure, Shenzhen, 518060, China \\ ${ }^{2}$ Professor, Department of Architecture and Building Engineering, Kanagawa University, Yokohama, 221-8686, Japan \\ ${ }^{3}$ Associate Professor, School of Civil Engineering and Architecture, Central South University, Changsha 410075, China
}

\begin{abstract}
In this paper, a model of the dynamic corrosion-induced cracking process of reinforced concrete (RC) structures considering the influence of initial defects in concrete cover caused by settlement of concrete is presented. Formulas for predicting time to initial defects initiation, time to cover cracking, threshold expansive pressure and critical weight loss of reinforcing steel are proposed. Comparisons with published experimental data show that the predictions given by the present model are in a good agreement with the experimental results and have better precision than other existing models. Finally, the influences of initial defects on critical corrosion-induced cracking indexes, such as time to initial defects initiation, time to cover cracking, threshold expansion pressure and critical weight loss of reinforcing steel are investigated. It was found that the initial defects have a great effect on critical corrosion-induced cracking indexes. These critical indexes decrease sharply when the size of initial fine crack is less than $1 \mathrm{~mm}$ or its number is smaller than 2 respectively, but tend to moderate when the size of the initial fine crack is more than $1 \mathrm{~mm}$ or its number is larger than 2. Therefore, it is important to improve the compactness of concrete in order to improve the durability of $\mathrm{RC}$ structures.
\end{abstract}

Keywords: initial defects; dynamic corrosion-induced cracking process; RC structures; threshold index; stress intensity factor; heterogeneous anisotropic property

\section{Introduction}

The steel corrosion of reinforced concrete (RC) structures due to chloride ingress followed by its deterioration is a growing and serious problem throughout the world. It is therefore of great importance for service life predictions, both for existing and planned structures ${ }^{1)}$.

Service life is generally defined as the time from construction to the first crack of a concrete surface resulting from the expansion of the reinforcement corrosion products. Of interest here is the dynamic corrosion-induced concrete cracking process including crack initiation, propagation and cover spalling stages. As is well known, the critical values in the cracking process, especially the time to cover cracking, are very important for modeling the time to repair, rehabilitate, and replace reinforced concrete structures in corrosive environments.

\footnotetext{
*Contact Author: Xiao-Gang Zhang, Associate Professor, College of Civil Engineering, Shenzhen University, Shenzhen, 518060, China

Tel: +86-7552-653-5212 Fax: +86-7552-673-2850

E-mail: bszxg@126.com

(Received October 8, 2009 ; accepted April 21, 2010)
}

\section{Research Significance}

Considerable research has been undertaken on corrosion-induced cover-cracking time and different analytical and empirical models ${ }^{2)-10)}$ have been suggested to predict the time to cover cracking. In these models, concrete with embedded reinforcing steel bars is generally modeled as a thick (thin)-walled cylinder $^{2)-10)}$ and the time to cover cracking is derived from the theory of elasticity based on the assumptions that concrete is a homogeneous and isotropic material, which does not consider the initial defects in concrete. However, as is well known, concrete is a non-isotropic heterogeneous compound material, composed of cement as well as other cementitious materials such as fly ash and slag cement, aggregate (including coarse aggregate and fine aggregate), water, and chemical admixtures. Many initial defects such as micro pore structures and random fine cracks occur during the formation of the concrete mixture. The initial defects may have a great effect on the stress field in concrete resulting from corrosion products and thus affect the time to cracking, especially on the scale of the cover $(<100 \mathrm{~mm})$. Further, there is a great difference between the stress field results that consider certain fine flaws and those obtained from the theory of elasticity with homogeneous and isotropic assumptions ${ }^{11)}$. As a result, the heterogeneity of concrete must be taken 
into account if more precise cover cracking is studied. However, a review of the published literature reveals that the effects of initial defects on the corrosioninduced cracking process have not been taken into account up until now.

In past decades, most of the research focused on the time to cover cracking and the corresponding critical expansion pressure. However, based on the fracture theory of concrete, corrosion-induced cover cracking is a dynamic process that is composed of crack initiation, propagation and cover spalling stages. Up to now, cracking of cover is generally defined by the appearance of the first visible crack on the surface of concrete. However, the fine cracks around reinforced bar have already undergone the initiation and propagation process before the first visible crack on the surface of concrete is observed. The initiation of cracks is important, because once started the propagation process is ineluctable. For accelerated experiments in the laboratory, it can be considered that the time to cover cracking and the time to crack initiation are the same, but in practical engineering, due to the natural lasting corrosion, there is a step-bystep propagation process for the corrosion-induced cover cracking. The time at which the surface crack is observed cannot represent the time of crack initiation. The existence of initial defects and their propagation in the concrete cover has a long-term influence on the corrosion cracking process. This process is realized by the gradual increase of the corrosion products. As a result, more attention should be paid to the dynamic corrosion-induced cover cracking process.

The object of the present paper is to investigate the dynamic corrosion-induced cracking process of RC structures considering the influence of initial defects caused by the settlement of concrete. Formulas for predicting the time to initial defects initiation, time to cover cracking, threshold expansion pressure and critical weight loss of reinforcing steel are proposed. To demonstrate the validity of the present model, comparisons of the predicted results are made with published experimental data on concrete slabs and cylindrical specimens. It is found that the predictions given by the present model are in a good agreement with the experimental results and have better precision than other existing models.

\section{Review of Analytical Models for Time to Cracking}

The cover cracking time due to steel corrosion has been studied experimentally and theoretically by many researchers. By assuming concrete to be a homogeneous elastic material, Bazant (1979) firstly gave a formula to predict time to cracking as follows ${ }^{2}$ :

$$
t=\rho_{r} 4 r_{1} \cdot \Delta r / S_{b} \cdot j_{r}
$$

where $r_{1}$ is the radius of the reinforcement bar, $\Delta r_{1}$ is the change in radius of the bar, $S_{b}$ is the spacing of the bars, $j_{r}$ is the rate of rust production, and $\rho_{r}$ is mass density of the expansive corrosion products.

After that an empirical model of time to cracking was given by Morinaga [1989] ${ }^{3)}$, which is expressed as:

$$
t=Q_{c r}^{2} / i_{c o r}
$$

where $i_{c o r}$ is the annual mean corrosion rate, $Q_{c r}$ is the critical mass of corrosion products consumed in the cover cracking process $\left(10^{-4} \mathrm{gms} / \mathrm{cm}^{2}\right)$, and $Q_{c r}$ is given by:

$$
Q_{c r}=1.204 \cdot r_{1} \cdot\left(1+C / r_{1}\right)^{0.85}
$$

where $c$ is the concrete cover thickness.

The models given by Bazant and Morinaga did not consider the thickness of the porous zone $\delta$ at the interface between the reinforcing bar and concrete, as a result, another model of time to cracking $t$ (in years) is given by Liu and Weyers ${ }^{4)}$ as:

$$
t=W^{2} / 2 k_{s}
$$

where $k_{s}$ is function of the rate of metal loss and is expressed as:

$$
k_{s}=0.196 \cdot \alpha \cdot \pi \cdot r_{1} \cdot i_{c o r}
$$

$\alpha$ is the ratio of molecular weight of iron to the molecular weight of corrosion products, $i_{c o r}$ is the constant annual mean corrosion rate $\left(\mu \mathrm{A} / \mathrm{cm}^{2}\right)$ and $W$ is the mass of steel per unit length of the reinforcement being consumed by the corrosion process $(\mathrm{mg} / \mathrm{mm})$. The determination of $W$ and $t$ was presented in Liu and Weyers ${ }^{4)}$. The corresponding calculation method was improved by Bhargava et al. ${ }^{7)}$.

Time-to-cover cracking models from different points of view were established in all of the references mentioned above, but these models are based on the theory of elasticity that considers that the plate cirque endures uniform expansive pressure along the round hole, which results in the elastic stress and strain fields of the concrete cover. Some of the results are consistent with the experimental data themselves, but deviate from others, as analyzed by Bhargava et al. ${ }^{7)}$. The main reason for the previous models' inferior precision may be derived from ignoring the existence of initial defects in the concrete, and not considering the effect of their propagation in the cover concrete.

\section{Dynamic Corrosion-induced Cracking Process Model Considering Initial Defects}

As described above, the initial defects in concrete are inevitable. These initial defects result from many factors such as settlement of concrete, the instability of cement, hydration heat temperature difference, alkaliaggregate reactions, bleeding, curing and concrete vibration. Different influencing factors will cause variant forms of initial defects in different areas of concrete cover. The initial defects may exist near the bar surface, middle of the concrete cover, other areas 
or even on the surface of the concrete cover.

As is well known, settlement of concrete is the main important factor inducing initial defect emanating from the bar surface at the interface between the reinforcing bar and concrete. In this paper, without loss of generality, focus is placed on the initial defect emanating from the bar surface caused by the settlement of concrete. The initial defect is assumed to be fine cracks and its effect on the corrosion-induced crack growth will be taken into account (Fig.1.).

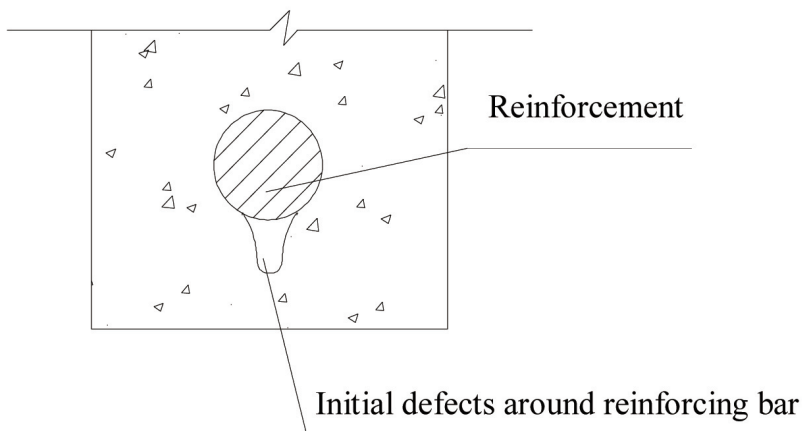

Fig.1. The Initial Defects of Concrete Around a Reinforcing Bar

Because the theory of fracture mechanics was developed to cope with problems such as "how does a crack propagate in a component being analyzed with an initial crack", it will be introduced to study the dynamic cracking process in corroded RC structures considering the influence of initial defects. Concrete with embedded reinforcing steel bars can be modeled as a thick-walled cylinder, as shown in Fig.2.a, in which $a$ is the length of a fine crack. Initially the porous fine crack will be gradually filled with the corrosion products and at this stage, the concrete is not subjected to any pressure. After the filling of the porous fine crack, the free expansion of corrosion products is restrained by concrete. At this stage, further formation of corrosion products will subject concrete to an internal pressure $p$ on the inner surface of the bar (Fig.2.b). Eventually when the stress intensity factor of the concrete cover exceeds its fracture toughness (Fig.2.c), the crack will propagate to the surface of the concrete cover, and the stress intensity factor is given by ${ }^{12)}$ :

$$
K_{I}=F_{i} P \sqrt{\pi a}
$$

in which $P$ is the internal pressure on the inner surface, $i$ is 1 or 2, that is, $F_{1}$ is for one crack and $F_{2}$ is for multiple cracks. $F_{1}$ is expressed as:

$$
\begin{gathered}
F_{1}=\frac{A_{1} /(\ln b)^{0.3}+A_{2} /(\ln b)^{0.8}}{\sqrt{1-(1 / b)^{0.25}}} \\
A_{1}=0.854-1.812(a / c)^{0.5}-0.212(a / c)^{2} \\
A_{2}=-0.114+1.193(a / c)^{0.5}+0.656(a / c)^{2}
\end{gathered}
$$

where $b$ is the radius ratio $b=r_{2} / r_{1}$.

$F_{2}$ is expressed as:

$$
\begin{gathered}
F_{2}=\frac{\left(B_{1}+B_{2}(a / c)^{.25}+B_{3}(a / c)^{p s}\right) / \ln b+\left(B_{4}+B_{5}(a / c)^{0.25}+B_{6}(a / c /)^{1.5}\right) /(\ln b)^{1.2}}{\sqrt{\left[1.2-(a / c)^{2}\right]\left[1.3+(1 / \ln b)^{0.25}\right]}} \\
B_{1}=\left(2.817-\frac{692.667}{(n+3)^{0.75}}+\frac{1615.269}{(n+3)}-\frac{2744.824}{(n+3)^{2}}\right) / \sqrt{1+\left(\frac{1}{n+3}\right)^{2}} \\
B_{2}=\left(-4.525-\frac{996.259}{(n+3)^{0.75}}+\frac{2399.393}{(n+3)}-\frac{4364.677}{(n+3)^{2}}\right) / \sqrt{1+\left(\frac{1}{n+3}\right)^{2}} \\
B_{3}=\left(1.975-\frac{513.949}{(n+3)^{0.75}}+\frac{1288.69}{(n+3)}-\frac{2544.936}{(n+3)^{2}}\right) / \sqrt{1+\left(\frac{1}{n+3}\right)^{2}} \\
B_{4}=\left(-2.522+\frac{739.698}{(n+3)^{0.75}}-\frac{1645.058}{(n+3)}+\frac{2615.106}{(n+3)^{2}}\right) / \sqrt{1+\left(\frac{1}{n+3}\right)^{2}} \\
B_{5}=\left(4.18-\frac{1048.678}{(n+3)^{0.75}}+\frac{2428.209}{(n+3)}-\frac{4160.596}{(n+3)^{2}}\right) / \sqrt{1+\left(\frac{1}{n+3}\right)^{2}} \\
B_{6}=\left(-1.85+\frac{545.827}{(n+3)^{0.75}}-\frac{1264.289}{(n+3)}+\frac{2507.663}{(n+3)^{2}}\right) / \sqrt{1+\left(\frac{1}{n+3}\right)^{2}}
\end{gathered}
$$

where $n(n=1,2,3 \ldots)$ denotes the number of fine cracks.

The dynamic cracking process of concrete cover can be represented by the double- $K$ fracture criterion ${ }^{13-16)}$ of concrete as follows:

$$
\begin{array}{ll}
K_{I}<K_{\mathrm{Ic}}{ }^{i n i} & \text { no crack propagation } \\
K_{\mathrm{Ic}}{ }^{i n i} \leq K_{I} \leq K_{\mathrm{Ic}}{ }^{u n} & \text { Steady crack propagation } \\
K_{l}>K_{\mathrm{Ic}}{ }^{2 n} & \text { unsteady crack propagation }
\end{array}
$$
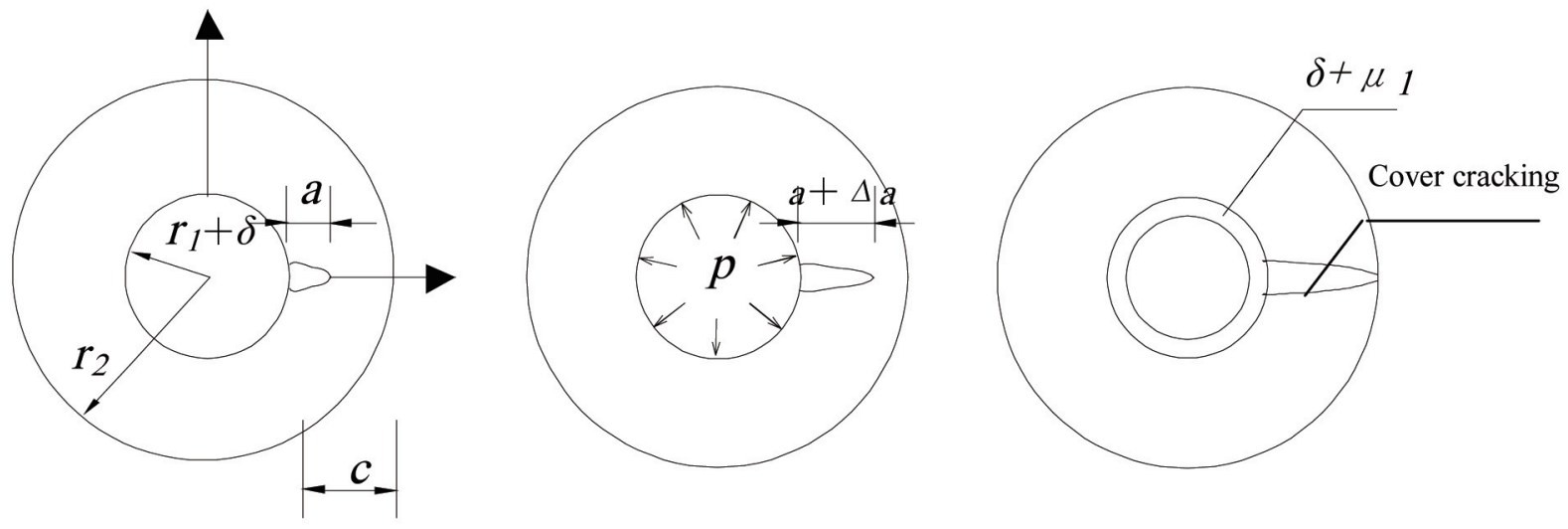

(a) Depassivation and filling full in pore, (b) the expansion pressure, (c) the growth of fine cracks Fig.2. The Dynamic Corrosion-induced Cracking Process of Concrete Cover 
where $K_{I}$ is the stress intensity factor expressed in Eq.(6), $K_{I c}{ }^{i n i}$ is the initial fracture toughness and $K_{I c}{ }^{u n}$ is the unstable fracture toughness which are the socalled double- $K$ fracture parameters. A number of experimental tests have been performed to determine the double- $K$ fracture parameters, and it was found that the double- $K$ fracture parameters can be considered the material parameters to describe the crack initiation and growth process for concrete ${ }^{13-16)}$. In order to gain the fracture parameters of corrosion-induced cracking, one should consider the size effect of these parameters because the thickness of the concrete cover is generally less than $100 \mathrm{~mm}$ in practice. In the paper, the concrete cover around the corroded reinforcing bars is modeled as a fixed beam subject to uniform inner pressure, as shown in Fig.3., to consider the size effect. This not only expresses the actual stress state of the concrete cover, but also effectively accords with the shape of the three-point bending notched beam which is used to evaluate the double- $K$ fracture parameters. As a result, the size effect and boundary effect of corrosion-induced concrete cover cracking can be well understood. The fracture toughness of corrosion-induced cracking after considering the size effect can be expressed as:

$$
K_{\mathrm{Ics}}=K_{\mathrm{I} c} \sqrt{\frac{c}{h}}\left(\frac{V}{2 r_{1} \cdot c}\right)^{1 / \alpha^{\prime}} \quad(h \leq 2 \mathrm{~m})(7)
$$

in which $h, V$, and $K_{I c}$ are, respectively, the height, volume and fracture toughness of the three-point bending notched beam. $\alpha^{\prime}$ is the Weibull modulus, which is related to the coefficient of variation of experimental values of unstable fracture toughness, and is given by:

$$
\alpha^{\prime}=\frac{\pi}{\sqrt{6.5} C_{v}} \quad\left(0.013 \leq C_{v} \leq 0.230\right)
$$

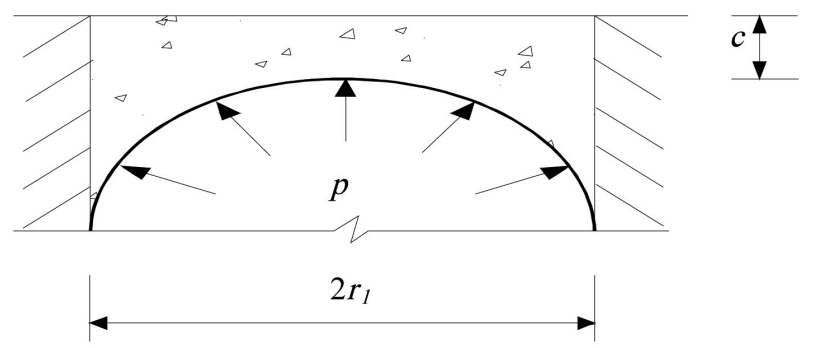

Fig.3. The Fixed-beam Model of Concrete Cover Subjected to Uniform Inner Pressure

The initial threshold expansion pressure $P^{i n i}$, deduced from the initial fracture toughness $K_{I c s}{ }^{i n i}$ of corrosioninduced cracking, means the time when the corrosioninduced pressure reaches the point at which the propagation of corrosion-induced cracking commences. In the same way, when the corrosion-induced pressure arrives at the threshold cracking pressure $P^{u n}$, deduced from the unstable fracture toughness $K_{\text {Ics }}^{u n}$ of corrosioninduced cracking, the concrete cover cracks.
According to Eq. (6), the initial threshold pressure $P^{i n i}$ can be given by:

$$
p^{i n i}=\frac{K_{\text {Ics }}^{i n i}}{F_{i} \sqrt{\pi a}}
$$

Similarly, the threshold cracking pressure $P^{u n}$ can be expressed as:

$$
p^{u n}=\frac{K_{\text {Ics }}^{\text {un }}}{F_{i} \cdot \sqrt{\pi\left(a+\Delta a^{*}\right)}}
$$

where $\Delta a_{c}{ }^{*}$ is the effective crack propagation length, which means the crack length will be $a+\Delta a_{c}{ }^{*}$ when the stress intensity factor becomes $K_{\text {Ics }}{ }^{u n}$. As a result, the softening character of concrete cover is considered. According to the fracture theory, there are many softening models of concrete such as single line, bilinear and parabola models. Because the thickness of the concrete cover is quite small compared to the height of the members, the parabola model is more suitable for the present case of small size (thickness of the concrete cover) than the conventional single line and bilinear softening models. Based on the research of Zhang et al. ${ }^{17)}$, it can be given by:

$$
\Delta a_{c}^{*}=\Delta a_{c}-r_{0}=r_{0}
$$

where $\Delta a_{c}$ is the length of fracture zone, and $r_{0}$ can be regarded as crevice genesis zone:

$$
r_{0}=\frac{1}{2 \pi}\left(\frac{K_{\text {Ics }}^{u n}}{f_{t}}\right)^{2}
$$

It should be noted that other methods exist to describe the softening character of concrete such as using the criterion of $C T O D_{c}$ (the critical crack tip opening displacement), which is not included in the paper.

When the surrounding concrete is subjected to a corrosion-induced pressure $p$, the corresponding mass of steel $(\mathrm{mg} / \mathrm{mm})$ per unit length of the reinforcement being consumed by the corrosion process $W$ and the time to cracking $t$ can be gained from the radial displacement of concrete $u_{1}$ at the surface of the reinforcing bars, and $u_{1}$ is given by ${ }^{4), 7)}$ :

$$
u_{1}=\frac{p\left(r_{1}+\delta\right)}{E_{e f}}\left[\frac{\left(r_{1}+\delta\right)^{2}+r_{2}^{2}}{r_{2}^{2}-\left(r_{1}+\delta\right)^{2}}+\mu\right]
$$

where $\mu$ is Poisson's ratio for concrete, and $E_{c f}$ is the effective modulus of elasticity of the cover concrete and is given as follows:

$$
E_{e f}=\frac{E_{c}}{1.0+\theta_{c}}
$$

where $E_{c}$ and $\theta_{c}$ are the initial tangent modulus and creep coefficient for the cover concrete, respectively.

When pressure $p$ arrives $P^{i n i}$, also displacement $u_{1}$ reaches $u_{1}^{i n i}$, the corresponding mass of steel $(\mathrm{mg} / \mathrm{mm})$ per unit length of the reinforcement being consumed by the corrosion process $W^{\text {ini }}$ and the time to fine crack initiation $t^{\text {ini }}$ can be expressed by Eq. (15) and Eq. (16) respectively, which mean the initiation of fine cracking: 


$$
\begin{aligned}
W^{i n i} & =\frac{\pi \rho_{s}\left[\left(r_{1}+\delta+u_{1}^{i n i}\right)^{2}-r_{1}^{2}\right]}{\alpha_{1}-1.0} \\
t^{i n i} & =\frac{\left(W^{i n i}\right)^{2}}{0.392 \pi \cdot r_{1} \cdot i_{c o r}(t) \cdot \alpha}
\end{aligned}
$$

Similarly, when $p$ arrives $P^{u n}$, also $u_{1}$ reaches $u_{1}^{u n}$, the corresponding $W^{u n}$ and $t^{u n}$ can be expressed by Eq. (17) and Eq. (18) respectively, which mean concrete cover cracking:

$$
\begin{aligned}
& W^{u n}=\frac{\pi \rho_{s}\left[\left(r_{1}+\delta+u_{1}^{u n}\right)^{2}-r_{1}^{2}\right]}{\alpha_{1}-1.0} \\
& t^{u n}=\frac{\left(W^{u n}\right)^{2}}{0.392 \pi \cdot r_{1} \cdot i_{c o r}(t) \cdot \alpha}
\end{aligned}
$$

where $\rho_{s}$ is the mass density of reinforcing steel, $\alpha_{1}$ is the ratio of the volume of expansive corrosion products to the volume of iron consumed in the corrosion process, which is determined in ${ }^{4), 7)}$.

From the above calculation process, one can see that the coupled effects of initial micro crack propagation, change of corrosion rate, creep of concrete cover and softening character of concrete on the critical corrosion-induced cracking indexes, such as time to fine crack initiation, time to cover cracking, threshold expansion pressure and critical weight loss of reinforcing steel time, are taken into account.

\section{Verification of Present Model}

Owing to the lack of finite elements or experimental analysis results concerning time to fine crack initiation in past researches, recent experimental investigations on the prediction of time to cover cracking conducted by Liu and Weyers ${ }^{4)}$ and Torres-Acosta and Sagüés ${ }^{6)}$ were used to verify the proposed formula in this study. Table 1 shows the experimental data of a 5-year study of outdoor-exposed slabs provided by Liu and Weyers ${ }^{4}$, and data from the cylindrical concrete specimens studied by Torres-Acosta and Sagüés ${ }^{6)}$ are listed in Table 2.

Table 1. Experimental Data for Slab Specimen in Liu and Weyers $^{4)}$

\begin{tabular}{ccccccc}
\hline $\begin{array}{c}\text { Specimen } \\
\text { designation }\end{array}$ & $\begin{array}{c}2 r_{l} \\
(\mathrm{~mm})\end{array}$ & $\begin{array}{c}f_{c m} \\
(\mathrm{MPa})\end{array}$ & $\begin{array}{c}c \\
(\mathrm{~mm})\end{array}$ & $\begin{array}{c}i_{c o r} \\
\left(\mu A \mathrm{~cm}^{2}\right)\end{array}$ & $\begin{array}{c}\text { Exposure } \\
\text { period } \\
(\text { years })\end{array}$ & $\begin{array}{c}\text { Observed } \\
\text { time } t \\
(\text { years })\end{array}$ \\
\hline S1 & 16 & 31.5 & 48 & 2.41 & 1.84 & 1.84 \\
S2 & 16 & 31.5 & 70 & 1.79 & 3.67 & 3.54 \\
S3 & 16 & 31.5 & 27 & 3.75 & 0.87 & 0.72 \\
S4 & 12.7 & 31.5 & 52 & 1.80 & 2.38 & 2.38 \\
\hline
\end{tabular}

The computation parameters of the present model are described as follows:

(1) The stable values of $K_{I c}^{i n i}$ and $K_{I c}{ }^{u n}$ for concrete are taken as $1.034 \mathrm{MPa} \cdot \mathrm{m}^{1 / 2}$ and $2.072 \mathrm{MPa} \cdot \mathrm{m}^{1 / 2}$, respectively, which are based on the experimental results of 20 three-point beams provided by $\mathrm{Wu}$ et $a l{ }^{18)}$. The corresponding coefficients of variation are 0.061 and 0.073 . It should be noted that the influencing factors of fracture toughness such as mixture ratio, the material composition in $\mathrm{Wu}$ et al. ${ }^{18)}$ are approximate with Liu and Weyers ${ }^{4)}$, which prove that the values of $K_{I c}^{i n i}$ and $K_{I c}^{u n}$ chosen in this paper are credible. Other
Table 2. Experimental Data for Cylindrical Concrete Specimen in Torres-Acosta and Sagüés ${ }^{6}$

\begin{tabular}{ccccccc}
\hline $\begin{array}{c}\text { Specimen } \\
\text { designation }\end{array}$ & $\begin{array}{c}2 r_{I} \\
(\mathrm{~mm})\end{array}$ & $\begin{array}{c}f_{c m} \\
(\mathrm{MPa})\end{array}$ & $\begin{array}{c}E_{c} \\
(\mathrm{MPa})\end{array}$ & $\begin{array}{c}c \\
(\mathrm{~mm})\end{array}$ & $\begin{array}{c}i_{\text {cor }} \\
\left(\mu \mathrm{A} / \mathrm{cm}^{2}\right)\end{array}$ & $\begin{array}{c}\text { Observed } \\
\text { time } t \\
(\text { days })\end{array}$ \\
\hline $\begin{array}{c}\text { CPA1 } \\
\text { CPA2 }\end{array}$ & 21 & 53 & 34471 & 27.5 & 100 & $\begin{array}{c}13 \\
17\end{array}$ \\
\hline $\begin{array}{l}\text { CPB1 } \\
\text { CPB2 }\end{array}$ & 21 & 50 & 33482 & 40.5 & 100 & $\begin{array}{c}24 \\
20\end{array}$ \\
\hline CPC1 & 21 & 53 & 34471 & 65.5 & 100 & 21 \\
CPC2 & & & & & & 28 \\
\hline CPD1 & 21 & 40 & 29947 & 40.5 & 100 & 18 \\
CPD2 & & & & & & 20 \\
\hline CPF1 & 21 & 53 & 34471 & 40.5 & 100 & 18 \\
CPF2 & & & & & & 17 \\
\hline
\end{tabular}

more experimental results also illustrate the same stable fracture toughness values ${ }^{13-16)}$.

(2) The values of $\delta, \alpha_{1}$ and $\mu$ ect are the same as those experimental or theoretical values adopted by Liu and Weyers ${ }^{4)}$ and by Bhargava ${ }^{7)}$ for the convenience of results comparison to prove the better precision of the present model. It should be noted that the influence of these computation parameters on final cracking time has been discussed by Liu and Weyers ${ }^{4)}$ and by Bhargava $^{7}$, which will not be included in this paper.

(3) As is well known, the settlement of concrete is a major important factor inducing initial defect. In engineering practice, the amount of concrete settlement is expected to be about $1 \%$ of its thickness (height) in general. The thickness (height) of the specimen in Liu and Weyers ${ }^{4)}$ and in Torres-Acosta and Sagüés ${ }^{6)}$ was $216 \mathrm{~mm}$ and about $200 \mathrm{~mm}$ respectively. As a result, the size of initial defects (length) is assumed to be 2 $\mathrm{mm}$.

The threshold expansion pressure, critical weight loss of reinforcing steel, and time to cover cracking predicted by the present method, compared with the experimental results of Liu and Weyers ${ }^{4}$ and TorresAcosta and Sagüés ${ }^{6)}$, are listed in Tables 3. and 4. respectively, together with model predictions of Liu and Weyers, Torres-Acosta and Sagüés, and Bhargava et $a l^{4), 6), 7)}$. As can be seen from Tables 3. and 4., the predicted time to cover cracking using the present method is in close agreement with the experimental results, which shows that the present model has good precision. At the same time, the present model provides much better results than the models of Liu and Weyers, Torres-Acosta and Sagüés, and Bhargava et al. ${ }^{4), 6), 7)}$. Similar conclusions can be drawn for the critical weight loss of reinforcing steel. For the threshold expansion pressure, the present method gives almost the same results as those of Liu and Weyers, Torres-

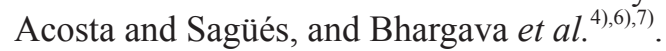

The changes in times to cover cracking with the thickness of the concrete cover depicted in Fig.4. are based on the experimental results of the cylindrical concrete specimen in Torres-Acosta and Sagüés ${ }^{6)}$. As can be seen from Fig.4., the time to cover cracking increases linearly with the increase of thickness of 
Table 3. Comparison of Experimental and Analytically Predicted Values for Slab Specimens

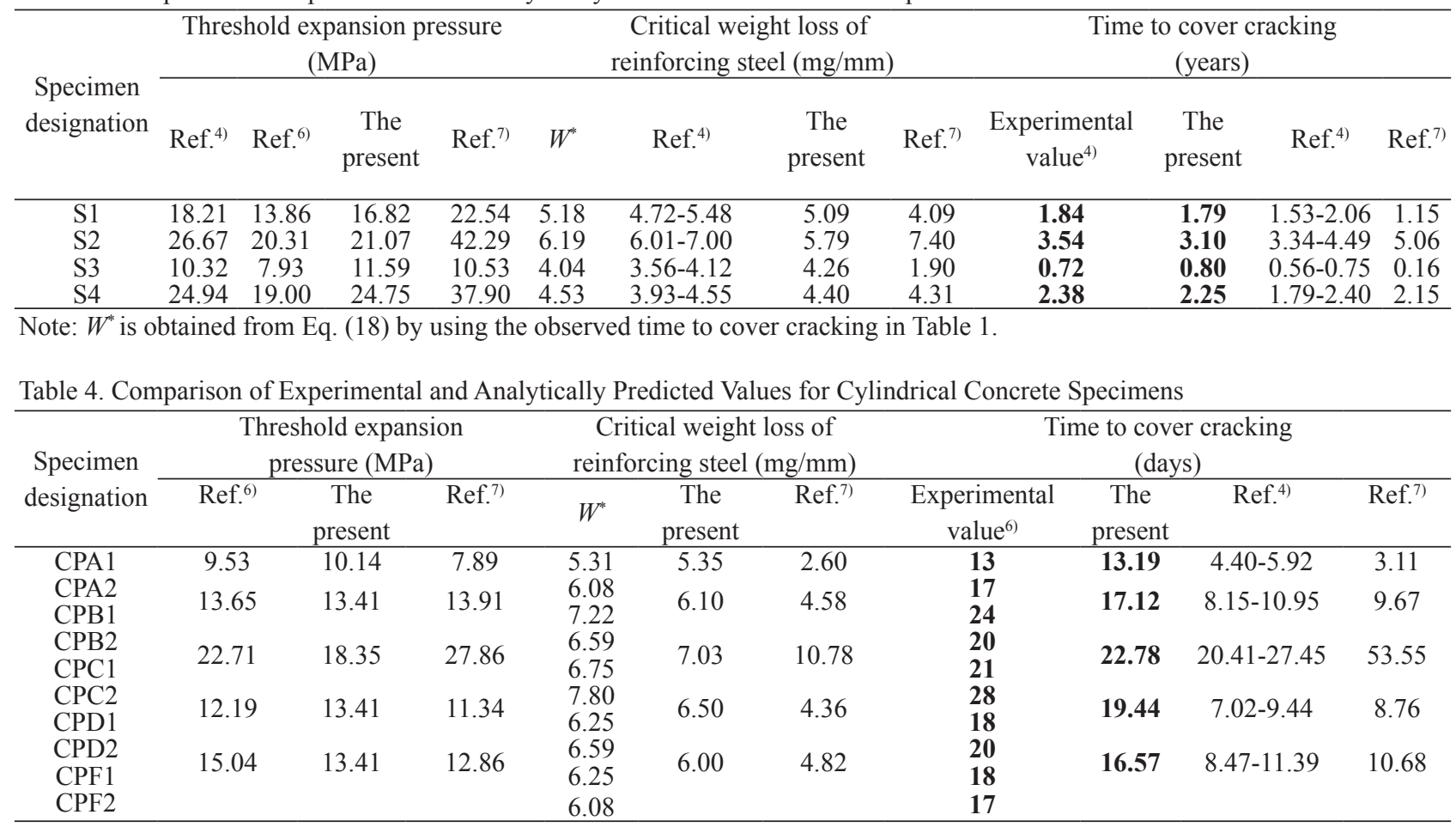

Note: $W^{*}$ is obtained from Eq. (18) by using the observed time to cover cracking in Table 2.

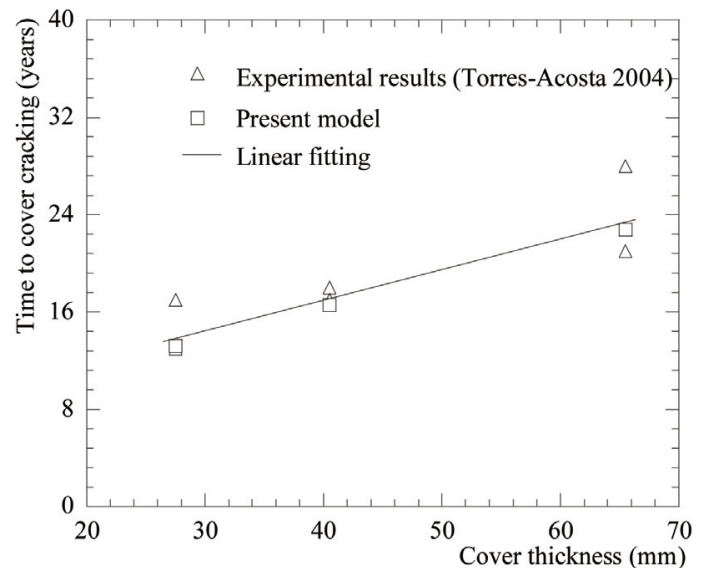

Fig.4. Relationship between Time to Cover Cracking and Concrete Cover Thickness

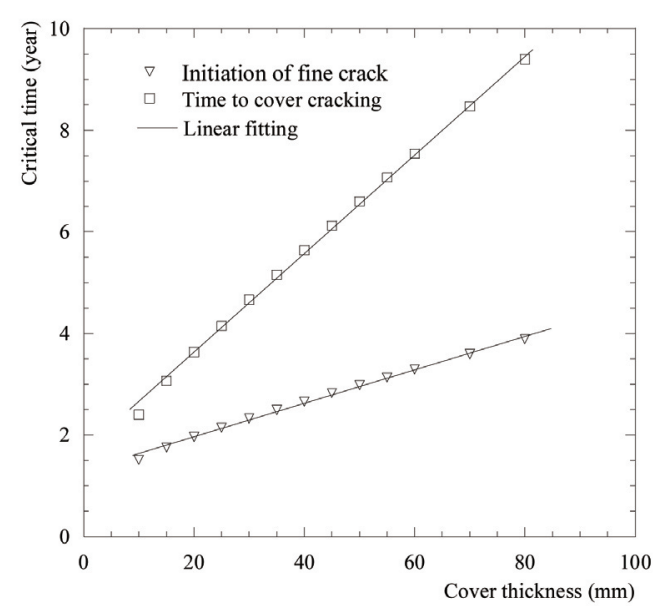

Fig.5. Linear Increase of Critical Time with Increase of Concrete Cover Thickness

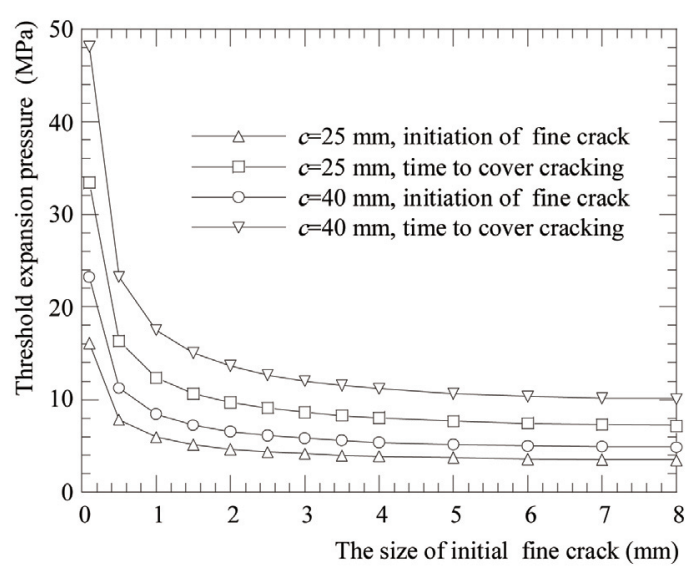

Fig.6. The Effect of Fine Crack Length on Threshold Expansive Pressure

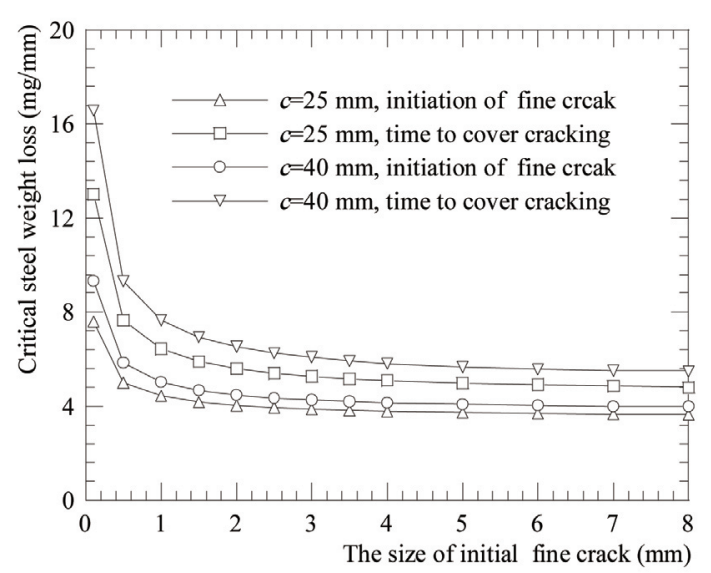

Fig.7. The Effect of Fine Crack Length on Critical Weight Loss of Reinforcing Steel 


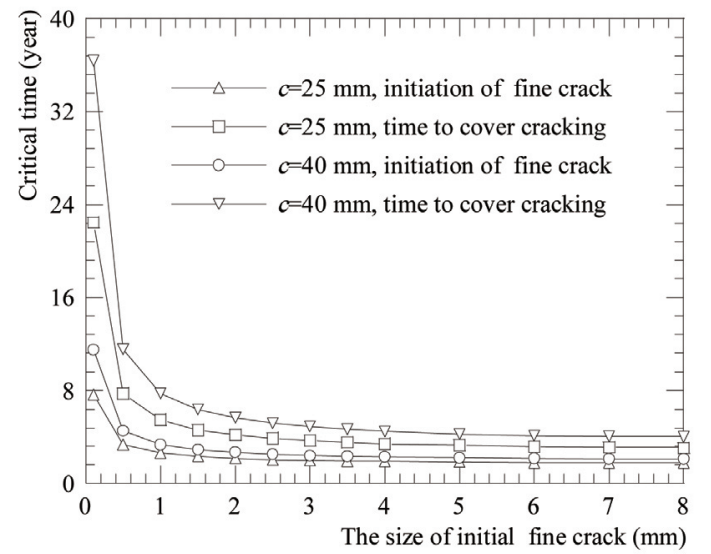

Fig.8. The Effect of Fine Crack Length on Time to Cover Cracking

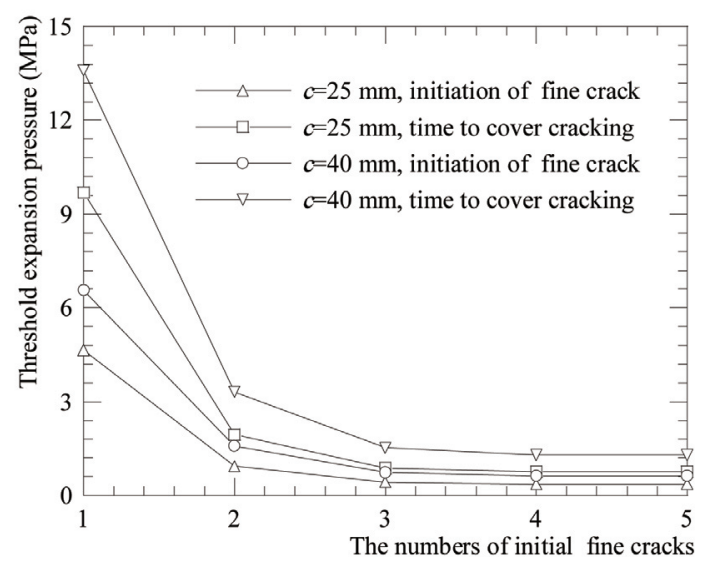

Fig.9. The Effect of Fine Crack Numbers on Threshold Expansive Pressure

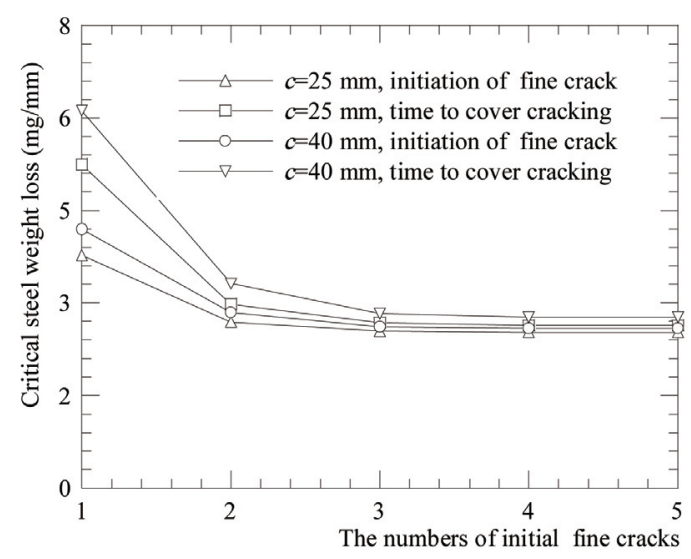

Fig.10. The Effect of Fine Crack Numbers on Critical Weight Loss of Reinforcing Steel

the concrete cover when the other parameters, such as diameter of reinforcing steel, concrete compressive strength and corrosion rate, remain constant. To verify this rule, the time to initial cracking and the time to cover cracking predicted by the present model with the variation of the thickness of concrete for $a=2 \mathrm{~mm}, r_{1}=$ $10 \mathrm{~mm}$, and $i_{c o r}=1 \mu \mathrm{A} / \mathrm{cm}^{2}$ is shown in Fig.5., from which one can see that as the thickness of the concrete cover increases, both the time to initial cracking and the time to cover cracking increase linearly: that is,

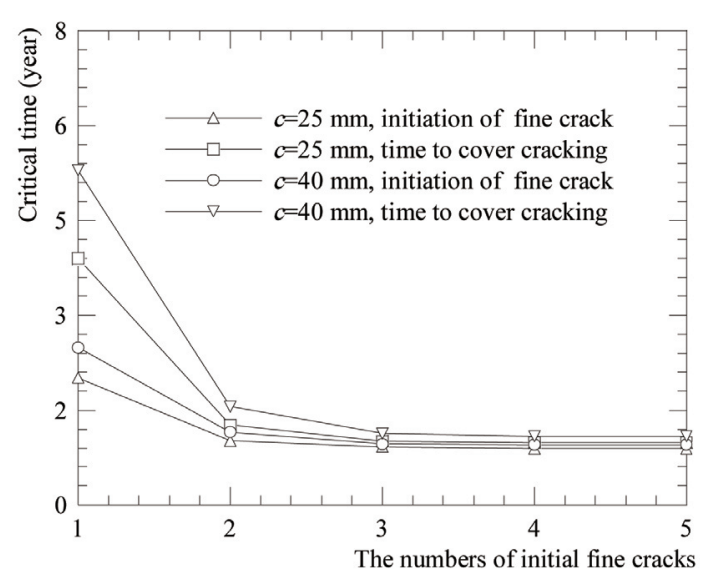

Fig.11. The Effect of Fine Crack Numbers on Time to Cover Cracking

the same tendency is obtained as illustrated by the experimental results ${ }^{6}$. Also, one can see that the differences between the time to initial cracking and the time to cover cracking increase as the thickness of the concrete cover increases. This means that the corrosion-induced cracking process tends to produce brittle fracture when the concrete cover is thin, which coincides with the phenomenon observed in the field study, while the growth process from the time of initial cracking to the time of cover cracking is steady if the concrete cover is thick. This process is more inclined to produce ductile fracture.

It should be noted that when Eq. (6) is used in the finite element method ${ }^{16)}$, the ratio of $a / c$ and the value of $b$ should be stratified according to the following conditions: $0.01 \leq a / c \leq 0.8$ (for one fine crack) and $0.1 \leq a / c \leq 0.7$ (for multiple cracks) and $1.5 \leq \mathrm{b} \leq$ 3.0. Nevertheless, even if the range of $a / c$ and $b$ are beyond the limitations, the computation results using Eq. (6) are in close agreement with the experimental results, as illustrated in Tables 3. and 4. Therefore, it is appropriate to compute the corrosion-induced crack growth by using Eq. (6).

\section{Effect of Initial Defects on Critical Corrosion- Induced Cracking Indexes}

The effect of the size of an initial fine crack on the threshold expansion pressure, critical weight loss of reinforcing steel, and time to cover cracking are depicted in Fig.6., Fig.7. and Fig.8., respectively. Initial fine cracks with sizes of $0.1 \mathrm{~mm}, 0.5 \mathrm{~mm}, 1$ $\mathrm{mm}, 1.5 \mathrm{~mm}, 2.5 \mathrm{~mm}, 3 \mathrm{~mm}, 3.5 \mathrm{~mm}, 4 \mathrm{~mm}, 5 \mathrm{~mm}$, $6 \mathrm{~mm}, 7 \mathrm{~mm}$ and $8 \mathrm{~mm}$ were considered. Without loss of generality, the corrosion rate $i_{c o r}$ is deemed to be $1 \mu \mathrm{A} / \mathrm{cm}^{2}$, which is the general mean value in nature ${ }^{19)}$, concrete covers with $25 \mathrm{~mm}$ and $40 \mathrm{~mm}$ thick are considered, and the other parameters are the same as those described in section 3. As can be seen from Figs.6., 7., and 8., the size of the initial fine crack has a great effect on the threshold cracking pressure, critical weight loss of reinforcing steel and time to cover cracking. The three critical indices decrease sharply 
when the size of the fine crack is less than $1 \mathrm{~mm}$. However, these indices are almost not affected by the size when it is more than $1 \mathrm{~mm}$. In the mean time, the difference in the threshold indices of the initial crack and cover cracking decreases as the size of the macro crack increases, i.e., the cracking process changes from ductile fracture to brittle fracture. When the size of the initial defect remains the same, the thicker is the concrete cover, the larger the corresponding threshold indices. It seems that the effect resulting from the existing initial defect is greater than the variation of the thickness of the concrete cover. Therefore, improving the compactness of concrete will improve the durability of RC structures.

Figs.9., 10., and 11., show the effects of numbers of initial fine cracks on the threshold cracking pressure, critical weight loss of reinforcing steel, and time to cover cracking, respectively, in which $a=2 \mathrm{~mm}$, and the other parameters are the same as those used in the above figures. As can be seen from Figs.9., 10., and 11., the number of initial fine cracks has a great effect on the threshold cracking pressure, critical weight loss of reinforcing steel, and time to cover cracking. The three critical indices decrease sharply when the number of initial fine cracks is smaller than 2. However, the values of these indices tend to moderate when the number of initial fine cracks is larger than 2 .

\section{Conclusions}

In this paper, a model of the dynamic corrosioninduced cracking process of RC structures that considers the influence of initial defects caused by the settlement of concrete is presented. Formulas for predicting the time to initial cracking, threshold expansion pressure, critical weight loss of reinforcing steel, and time to cover cracking are proposed. The influence of initial defects on the critical corrosion-induced crack index was analyzed, and it was found that:

(1) Comparisons with published experimental data show that the predictions given by the present model are in a good agreement with the experimental results and have better precision than other existing models.

(2) The time to cover cracking increases linearly with the increase in the thickness of the concrete cover when the other parameters, such as diameter of reinforcing steel, concrete compressive strength and corrosion rate, remain constant.

(3) The initial defects have a great effect on the threshold expansive pressure, critical weight loss of reinforcing steel, and time to cover cracking. These three critical indices decrease sharply when the size of initial fine cracking is less than $1 \mathrm{~mm}$ or its number is smaller than 2 respectively, but tend to moderate when the size of initial fine cracking is more than $1 \mathrm{~mm}$ or its number is larger than 2 .

Therefore, it is important to improve the compactness of concrete in order to improve the durability of $\mathrm{RC}$ structures.

\section{Acknowledgements}

This research was supported by the following projects: the National Natural Science Foundation of China (50908148, 50925829), Research Project of the Ministry of Housing and Urban-Rural Development of China (2009-K4-23), Shenzhen Key Lab on Durability of Civil Engineering Open Fund No. CED08-11, the Joint Research Fund for Overseas Chinese, Hong Kong and Macao Young Scholars (No.50828801) from the National Natural Science Foundation of China, and the startup funds from Central South University. The support is gratefully acknowledged.

\section{References}

1) M. Maage, S. Helland and E. Poulsen, Ø. (1996) Vennesland, J. E. Carlsen. Service life prediction of existing concrete structures exposed to marine environment. ACI Materials Journal, 93(6), pp. $1-8$.

2) Z.P. Bazant. (1979) Physical model for steel corrosion in sea structure-applications, J. Struct. Div., ASCE,105(6), pp.1155-1166.

3) S. Morinaga. (1989) Prediction of service lives of reinforced concrete buildings based on the rate of corrosion of reinforcing steel, Special report of the institute of technology, Shimizu Corporation, Japan.

4) Y. Liu and R. E. Weyers. (1998) Modeling the time-to-corrosion cracking in chloride contaminated reinforced concrete structures. ACI Materials Journal, 95(6), pp.675-681.

5) S. J. Pantazopoulou and K.D. Papoulia. (2001) Modeling covercracking due to reinforcement corrosion in RC structures. Journal of Engineering Mechanics, 127(4), pp.342-351.

6) A. A. Torres-Acosta and A. A. Sagüés. (2004) Concrete cracking by localized steel corrosion- geometric effects. ACI Materials Journal, 101(6), pp.501-507.

7) K. Bhargava, A. K. Ghosh, Y. Mori and S. Ramanujam. (2005) Modeling of time to corrosion-induced cover cracking in reinforced concrete structures. Cement and Concrete Research, 35, pp.2203-2218.

8) T. Maaddawy and K. Soudki. (2007) A model for prediction of time from corrosion initiation to corrosion cracking. Cement \& Concrete Composites, 29, pp.168-175.

9) S. Li, M. Wang and S. Li. (2008) Model for cover cracking due to corrosion expansion and uniform stresses at infinity. Applied Mathematical Modelling, 32(7), pp.1436-1444.

10) G. Xu, J. Wei, K. Zhang and X. Zhou. (2007) A calculation model for corrosion cracking in RC structures. Journal of China University of Geosciences, 1(18), pp.85-89.

11) Q.P. Wang. (2004) Experimental study and theoretic analysis on damage rule of corroded and cracked reinforced concrete. Dissertation Submitted to Hohai University, Nanjing P.R. China. (in Chinese).

12) Y. Murakami etc. (2001) Stress Intensity Factors Handbook (Vol. 4). The Society of Materials Science, Japan \& Elsevier Science Ltd, pp.289-296.

13) S. L. Xu and H. W. (1999) Reinhardt. Determination of double-K criterion for crack propagation in quasi-brittle fracture. Part III : Compact tension specimens and wedge splitting specimens. International Journal of Fracture, 98(2), pp.179-193.

14) S. L. Xu and H. W. Reinhardt. (1998) Crack extension resistance and fracture properties of quasi-brittle softening materials like concrete based on the complete process of fracture. International Journal of Fracture, 92(1), pp.71-99.

15) H. W. Reinhardt and S. L. Xu. (1999) Crack extension resistance based on the cohesive force in concrete. Engineering Fracture Mechanics, 64(5), pp.563-587.

16) S. L. Xu and H. W. (1998) Reinhardt. Analysis solution of the fictitious crack and evaluation of the crack extension resistance for a Griffith crack. In Mihashi H, Rokago K editors. Proceedings of Fracture Mechanics of Concrete Structures, FRAMCOS-3. Aedificatio Publishers Freiburg, 1, pp.409-420.

17) X. G. Zhang, Y. P. Song and Z. M. Wu. (2005) Calculation model of equivalent strength for induced crack based on double-K fracture theory and its optimizing setting in RCC arch dam. Transaction of Tian Jin university,11(1), pp.59-65.

18) Z. M. Wu, S. L. Xu and Y. Ding. (2001) The double-K fracture parameter of concrete for non-standard three point bending beam specimens. China Engineering Science, 3(4), 76-81 (in Chinese).

19) M. G. Stewart and D. V. Rosowsky. (1998) Time-dependent reliability of deteriorating reinforced concrete bridge decks. Structural Safety, 20, pp.91-109. 